\title{
Nutritional Status of Under-Five Children in Western Nepal
}

\author{
Shrestha B $^{1}$
}

\begin{abstract}
Introduction: Undernutrition is a major health problem in developing countries which may have adverse effects on growth and development of an individual. The objectives of this study were to assess the prevalence and grades of malnutrition in children below 60 months of age, attending outpatient department at Gandaki Medical College teaching hospital. Materials and Methods: A prospective study was conducted among 556 children below 60 months of age from August to December 2013. Weight and length/height were measured using standard technique and were plotted on WHO centiles curves and severity determined based on WHO classification. The prevalence of underweight, stunting and wasting were determined by anthropometry. Results: Based on WHO classification, out of 556 children, 20.2\% were underweight, $34 \%$ were stunted and $15.1 \%$ were wasted respectively. Of them, severe underweight were $4.7 \%$, severe stunted were $14.1 \%$ and severe wasted were $7.2 \%$ respectively. Conclusion: $A$ high prevalence of undernutrition exists in under- five children attending a tertiary hospital in a western region of Nepal.
\end{abstract}

Key words: Anthropometry, Under five children, Undernutrition

\section{Introduction}

U nder nutrition is a major global public problem in the developing countries. It directly or indirectly affects many aspects of the child's health which may have adverse effects on growth and development and also the child's ability to learn and process information and grow into adults. World Health Organization (WHO) estimated globally of around 6.6 million under five children died in the year 2012. Under nutrition is the underlying cause of death in an estimated $45 \%$ of all deaths among children under five years of age ${ }^{1}$.

Nepal Demographic and Health Survey 2011 (NDHS) shows $41 \%$ of children below five years of age are stunted, $29 \%$ of the children are underweight and $11 \%$ of the children below five years are wasted ${ }^{2}$. Under nutrition is not evenly distributed throughout Nepal; it varies both ecologically and regionally. Exact data of under nutrition attending a tertiary hospital of western region of Nepal is not known.
'Dr. Bandana Shrestha, Department of Paediatrics, Gandaki Medical College Teaching Hospital and Research Centre, Pokhara, Nepal.

\author{
Address for correspondence: \\ Dr. Bandana Shrestha \\ Department of Paediatrics, \\ Gandaki Medical College Teaching Hospital and \\ Research Centre, Pokhara, Nepal \\ E-mail: bandana139@yahoo.com \\ Phone: 9846029000
}

\section{How to cite}

Shrestha B. Nutritional Status of Under-Five Children in Western Nepal. J Nepal Paediatr Soc 2014;34(2):119-124.

doi: http://dx.doi.org/10.3126/jnps.v34i2.10566

This work is licensed under a Creative Commons Attribution 3.0 License.

\section{(c) (i)}

Therefore the objective of this study was to know the prevalence of three indicators of undernutrition that is, stunting, underweight and wasting among the under five children attending the tertiary hospital of western region. It also aims to identify the grades of under nutrition and its relation to different age groups, sex and ethnicity.

\section{Materials and Methods}

This was a prospective study conducted among the 556 children below 60 months of age attending out-patient department at Gandaki Medical College Teaching Hospital, Pokhara from August 2013 to December 2013. Consent was taken from all the parents before the assessment. All children aged one month to sixty months of age attending 
the paediatric outpatient department were included in the study. The children whose duration of illness exceeded seven days, diarrhoea with moderate to severe dehydration and gross congenital malformation were excluded from this study so as to exclude the child with under nutrition due to chronic illnesses. Ethical approval was taken from the Institutional Review Board (IRB) of Gandaki Medical College.

Each of the individual who were more than 24 months of age were weighed barefoot with minimal clothing using a standard electronic weighing machine which was kept on the hard and plane surface on the ground to avoid the error on recording. Weight was recorded nearest to $0.1 \mathrm{~kg}$. Body length was taken in children less than 24 months of age and was measured nearest to $0.5 \mathrm{~cm}$ by standard technique using infantometer in recumbent position. Height in older children was taken nearest to $0.5 \mathrm{~cm}$ on the stadiometer.

Weight and height of the boys and girls were compared to those of same aged boys and girls of NCHS/WHO standard. Based on the WHO classification, the $z$-scores $<-2.0$ was considered to classify stunted, wasted and underweight children based on their HAZ (height for age $\mathrm{z}$ score), WHZ (weight for height z score) and WAZ (weight for age $z$ score) values respectively. Similarly severe wasting and stunting were defined when weight for height and height for age z-scores < -3. Mean and standard deviation were calculated. All the data were calculated using SPSS version 16 . The chi-square test was used for assessing the significance of nutritional indices and independent variables of interest. A probability level of $\leq 0.05$ was considered to be statistically significant.

\section{Results}

Out of 556 children enrolled in this study, 346 (62.2\%) were males and 210 (37.8\%) were females (Table 1). According to the recent classification of ethnicity in Nepal, most belonged to upper caste $(n=305$; $54.85 \%$ ) followed by relatively advantaged janajati ( $n=$ $88 ; 15.82 \%)$, Dalit ( $n=78 ; 14.02 \%)$ and disadvantaged janajati ( $n=77 ; 13.84 \%$ ). None of the child attending OPD belonged to the religious minorities.

The overall prevalence of underweight, stunting and wasting in this study in reference to WHO growth chart based on WHO classification were $20.2 \%(n=112)$, $34.5 \%(n=193)$ and $15.1 \%(n=84)$ respectively (Table 2). Of them, $4.7 \%$ were severely underweight, $14.1 \%$ were severely stunted and $7.2 \%$ were severely wasted (Table 2). Underweight and stunting among the boys were significantly more compared to girls [ $(p=0.003$ for underweight and $p=0.002$ for stunting) (Table 3 and 4)]. There was significant association of underweight and stunting among the different ethnics groups $[(p=0.01$ for underweight and $p=0.006$ for stunting) (Table 3 and $4)$ ]. But the association of wasting with sex, ethnicity and age groups were not found to be statistically significant (Table 5).

Table 1: Distribution of study population

\begin{tabular}{|c|c|c|c|c|c|c|}
\hline \multirow{2}{*}{$\begin{array}{c}\text { Age Groups } \\
\text { (Months) }\end{array}$} & \multicolumn{2}{|c|}{ Male } & \multicolumn{2}{|c|}{ Female } & \multicolumn{2}{|c|}{ Total } \\
\hline & No. & $\%$ & No. & $\%$ & No. & $\%$ \\
\hline 1 to 6 & 52 & 9.31 & 30 & 5.3 & 82 & 14.7 \\
\hline 7 to 12 & 83 & 14.91 & 40 & 7.19 & 123 & 22.1 \\
\hline 13 to 24 & 79 & 14.21 & 51 & 9.17 & 130 & 23.4 \\
\hline 25 to 36 & 61 & 10.91 & 36 & 6.4 & 97 & 17.4 \\
\hline 37 to 48 & 42 & 7.5 & 22 & 3.9 & 64 & 11.5 \\
\hline$>48$ & 29 & 5.2 & 31 & 5.5 & 60 & 10.8 \\
\hline Total & 346 & 62.23 & 210 & 37.77 & 556 & 100 \\
\hline
\end{tabular}

Table 2: Nutritional status of the participants using the Height-for-age Z-scores (HAZ) and Weight-for-Age Z- scores (WAZ) and weight -for- height Z scores (WHZ)

\begin{tabular}{|l|c|c|c|c|c|c|}
\hline \multirow{2}{*}{$\begin{array}{l}\text { Grades of } \\
\text { Nutritional status }\end{array}$} & \multicolumn{2}{|c|}{ HAZ } & \multicolumn{2}{c|}{ WAZ } & No. & \% \\
\hline So. & $\mathbf{7 9}$ & 14.2 & 26 & 4.7 & 40 & 7.2 \\
\hline Modere & 114 & 20.5 & 86 & 15.5 & 44 & 7.9 \\
\hline Normal & 363 & 65.3 & 444 & 79.9 & 472 & 84.9 \\
\hline Total & $\mathbf{5 5 6}$ & $\mathbf{1 0 0}$ & $\mathbf{5 5 6}$ & $\mathbf{1 0 0}$ & $\mathbf{5 5 6}$ & $\mathbf{1 0 0}$ \\
\hline
\end{tabular}


Table 3: Distribution of weight for age z score( WAZ)

\begin{tabular}{|c|c|c|c|c|c|c|c|}
\hline \multirow[t]{2}{*}{ Characteristics } & \multicolumn{2}{|c|}{ Normal } & \multicolumn{2}{|c|}{ Moderate underweight } & \multicolumn{2}{|c|}{$\begin{array}{c}\text { Severe } \\
\text { underweight }\end{array}$} & \multirow[t]{2}{*}{$p$-value } \\
\hline & No & $\%$ & No & $\%$ & No & $\%$ & \\
\hline \multicolumn{8}{|l|}{ Gender } \\
\hline Male & 266 & 76.9 & 56 & 16.2 & 24 & 6.9 & \multirow{2}{*}{0.003} \\
\hline Female & 178 & 84.7 & 30 & 14.3 & 2 & 1.0 & \\
\hline \multicolumn{8}{|l|}{ Age groups (months) } \\
\hline$\leq 6$ & 66 & 80.5 & 15 & 18.3 & 1 & 1.2 & \multirow{6}{*}{0.144} \\
\hline $7-12$ & 103 & 83.7 & 17 & 13.8 & 3 & 2.4 & \\
\hline $13-24$ & 107 & 82.3 & 12 & 9.2 & 11 & 8.5 & \\
\hline $25-36$ & 73 & 75.3 & 18 & 18.5 & 6 & 6.2 & \\
\hline $37-48$ & 48 & 75 & 13 & 20.3 & 3 & 4.7 & \\
\hline$\geq 48$ & 47 & 78.3 & 11 & 18.3 & 2 & 3.3 & \\
\hline \multicolumn{8}{|l|}{ Ethnicity } \\
\hline Dalit & 63 & 80.8 & 12 & 15.4 & 3 & 3.8 & \multirow{5}{*}{0.015} \\
\hline Disadv janajati & 71 & 88.8 & 6 & 7.5 & 3 & 3.7 & \\
\hline R Adv janajati & 82 & 88.2 & 6 & 6.5 & 5 & 5.4 & \\
\hline Upper Caste & 228 & 74.8 & 62 & 20.3 & 15 & 4.9 & \\
\hline Total & 444 & 79.9 & 86 & 15.5 & 26 & 4.7 & \\
\hline
\end{tabular}

Disadvantaged janajati= Disadvantaged janajti; R Advantaged janajati= Relatively Advantaged janajati

Table 4: Distribution of height for age z score( HAZ)

\begin{tabular}{|c|c|c|c|c|c|c|c|}
\hline \multirow{2}{*}{ Characteristics } & \multicolumn{2}{|c|}{ Normal } & \multicolumn{2}{|c|}{ Moderate stunting } & \multicolumn{2}{|c|}{ Severe stunting } & \multirow{2}{*}{$p$-value } \\
\hline & No & $\%$ & No & $\%$ & No & $\%$ & \\
\hline \multicolumn{8}{|l|}{ Sex } \\
\hline Male & 208 & 60.1 & 77 & 22.3 & 61 & 17.6 & \multirow{2}{*}{0.002} \\
\hline Female & 155 & 73.8 & 37 & 17.6 & 18 & 8.6 & \\
\hline \multicolumn{8}{|l|}{ Age groups (months) } \\
\hline$\leq 6$ & 74 & 90.2 & 7 & 8.5 & 1 & 1.2 & \multirow{6}{*}{0.000} \\
\hline $7-12$ & 87 & 70.7 & 22 & 17.9 & 14 & 11.4 & \\
\hline $13-24$ & 70 & 53.8 & 34 & 26.2 & 26 & 20 & \\
\hline $25-36$ & 57 & 58.8 & 20 & 20.6 & 20 & 20.6 & \\
\hline $37-48$ & 33 & 51.6 & 18 & 28.1 & 13 & 20.3 & \\
\hline$\geq 49$ & 42 & 70.0 & 13 & 21.7 & 5 & 8.3 & \\
\hline \multicolumn{8}{|l|}{ Ethnicity } \\
\hline Dalit & 55 & 70.5 & 13 & 16.7 & 10 & 12.8 & \multirow{5}{*}{0.006} \\
\hline Dis Adv janajati & 62 & 77.5 & 11 & 13.8 & 7 & 8.8 & \\
\hline R Adv janajati & 70 & 75.3 & 14 & 15.1 & 9 & 9.7 & \\
\hline Upper caste & 176 & 57.7 & 76 & 24.9 & 53 & 17.4 & \\
\hline Total & 363 & 65.3 & 114 & 20.5 & 79 & 14.2 & \\
\hline
\end{tabular}

Disadvantaged janajati= Disadvantaged janajti; $R$ Advantaged janajati= Relatively Advantaged janajati 
Table 5: Distribution of weight for height z score ( $\mathrm{WHZ}$ )

\begin{tabular}{|c|c|c|c|c|c|c|c|}
\hline \multirow[t]{2}{*}{ Characteristics } & \multicolumn{2}{|c|}{ Normal } & \multicolumn{2}{|c|}{ Moderate wasting } & \multicolumn{2}{|c|}{ Severe } & \multirow{2}{*}{$p$-value } \\
\hline & No & $\%$ & No & $\%$ & No & $\%$ & \\
\hline \multicolumn{8}{|l|}{ Sex } \\
\hline Male & 288 & 83.2 & 27 & 7.8 & 31 & 9 & \multirow{2}{*}{0.118} \\
\hline Female & 184 & 87.6 & 17 & 8.1 & 9 & 4.3 & \\
\hline \multicolumn{8}{|l|}{ Age groups (months) } \\
\hline$\leq 6$ & 62 & 75.6 & 7 & 8.5 & 13 & 15.9 & \multirow{6}{*}{0.098} \\
\hline $7-12$ & 102 & 82.9 & 10 & 8.1 & 11 & 8.9 & \\
\hline $13-24$ & 111 & 85.4 & 12 & 9.2 & 7 & 5.4 & \\
\hline $25-36$ & 84 & 86.6 & 7 & 7.2 & 6 & 6.2 & \\
\hline $37-48$ & 58 & 90.6 & 4 & 6.2 & 2 & 3.1 & \\
\hline$\geq 48$ & 55 & 91.7 & 4 & 6.7 & 1 & 1.7 & \\
\hline \multicolumn{8}{|l|}{ Ethnicity } \\
\hline Dalit & 65 & 79.48 & 7 & 9.0 & 6 & 7.7 & \multirow{5}{*}{0.677} \\
\hline Disadv janajati & 72 & 90 & 2 & 2.5 & 6 & 7.5 & \\
\hline R Adv janajati & 77 & 82.8 & 9 & 9.7 & 7 & 7.5 & \\
\hline Upper Caste & 258 & 69 & 26 & 13 & 21 & 18 & \\
\hline Total & 472 & 84.9 & 44 & 7.9 & 40 & 7.2 & \\
\hline
\end{tabular}

Disadv janajati= Disadvantage janajti; $R$ Adv janajati= Relatively Advantage janajati

\section{Discussion}

Anthropometric indices are the major tool for assessing the nutritional status among the children by comparing them to a reference growth chart. Any deviation in anthropometric indices from the median value of the standard population is regarded as evidence of malnutrition. There are three indicators of malnutrition; underweight, stunting and wasting ${ }^{3}$.

Underweight is used as a composite indicator to reflect both acute and chronic under nutrition, although it cannot distinguish between them ${ }^{3}$. The overall prevalence of underweight in this study was $20.2 \%$ ( $n=112$ ). According to NDHS 2011 preliminary report, $29 \%$ children below five years are underweight ${ }^{2}$, which is more as compared to the present study. A study conducted by Thapa $\mathrm{M}$ et al found $28.2 \%$ children of Humla and $31.9 \%$ of Mugu were underweight ${ }^{4}$. Similarly a study in Western Kenya found 30\% of children were underweight ${ }^{5}$. But the prevalence of underweight from western region ${ }^{2}$ is only $23 \%$, which is comparable to the present study. High prevalence of underweight in various studies ${ }^{2,4,5}$ as compared to the present study might be because of the fact that the most of the study population in the present study were from the urban region whereas their study population were from rural areas.

This study showed that underweight was significantly more in boys compared to girls $(p=0.003)$.
Statistically, there was a significant association between underweight and gender of the study population (23.1\% boys Vs $15.3 \%$ girls). Two studies conducted in Nigerian children in two different settings also had a similar result with a higher prevalence of underweight in boys than in girls ${ }^{6,7}$. Similarly, higher prevalence of underweight in boys than girls was also noted in NDHS 2011 and a study conducted by Rijal $P$ et $\mathrm{al}^{2,8}$. This study further adds a small proportion (16.2\%) of children aged 7 to 12 months to be underweight but it drastically increased in the age group 37 to 48 months which has the highest prevalence of underweight $(n=$ $16 ; 25 \%)$ followed by the age groups 25 to 36 months ( $n=24 ; 24.7 \%$ ). A study by Shah $N^{9}$ conducted in Dhanusha district also reported a small proportion of children aged 7 to 12 months were underweight which is as comparable to the present study.

The overall prevalence of stunting in the current study was $34.71 \% \quad(n=193)$.Of them, boys were significantly stunted compared to girls (39.9\% Vs $26.2 \%$; $p=0.002$ ) and has an inverse linear association with the age of the child, being highest in the age groups of 37 to 48 months and lowest in children below six months of age. Studies conducted by NDHS 2011 in Nepal ${ }^{2}$ and Kandala NB in Democratic Republic of Congo ${ }^{10}$ showed similar results; boys were more stunted than girls. Most children at this age group (37-48 months) have a habit of eating junk food, which could be the reason contributing to chronic under nutrition in the form of stunting. In contrast, study conducted in 
Western Kenya found children in their second year of life were more likely to be underweight and stunted ${ }^{5}$. In addition, proportion of stunted children is noted least below six months of age in the current study which is comparable to the study conducted in Dhanusha district $^{9}$. Furthermore this study adds that the risk of stunting increases with age, and is comparable with other studies ${ }^{3,5}$. Children in the youngest age group below six months had a significantly lower risk of stunting than children in the older age group. It is likely that adequate maternal care during early life is protective and that stunting becomes more likely as the child grows and becomes dependent on extra food intake for growth ${ }^{9,11,12}$.

This study showed 84 (15.1\%) children are wasted, out of which half the children were severely wasted $(n=40)$. It was slightly higher than the NDHS report 2011. Similar studies conducted in Mugu, Humla and Dhankuta district found $9.4 \%, 8.8 \%$ and $11 \%$ of the children were wasted respectively ${ }^{4,12}$. These studies showed low prevalence of wasting compared to the present study. It is likely that the study populations enrolled were children attending OPD of the hospital and can have acute food deficit during the acute illness too. But the prevalence of wasting in this study is comparable to the similar study conducted by Rijal $\mathrm{P}$ who found $14.2 \%$ of the children were wasted ${ }^{8}$. Similar study conducted in Oromia found that $16.3 \%$ of the under five children were stunted which was similar to the present study ${ }^{13}$.

\section{Conclusion}

This study shows that malnutrition in the form of underweight, stunting and wasting still constitute a major health problem among the under five children from Western Region of Nepal. Of the three indicators of malnutrition, stunting is the commonest, indicating that chronic under nutrition existed as the commonest problem which is increasing as the child age increases.

\section{Limitation}

It was an institution based study to identify the prevalence of under nutrition in children. But it fails to predict the various factors which contributed under nutrition. A further study needs to be conducted to know the factors contributing to under nutrition among under-five children.

Acknowledgements: I would like to express my sincere thanks to Mrs. Bimala Sharma, MPH, Department of Community Medicine, Gandaki Medical College for her help in data analysis.
Funding: Nil

Conflict of Interest: None

Permission from IRB: Yes

\section{References}

1. World Health Organization. Millennium Development Goals (MDGs).[online]. 2014 May. Available from: URL : http://www.who.int/ mediacentre/factsheets/fs290/en/index.html

2. Population Division Ministry of Health and Population. Nepal Demographic and Health Survey 2011. New REA, ICF international Inc. 2012.

3. Ghai OP, Paul VK, Bagga A. Nutrition. In: Bharatnagar S, Lodha R, Bhatia V, Wadhwa N, Agarwala A editors. Ghai essential Pediatrics. 7th edition. New Delhi: CBS; 2009.p. 62 - 77.

4. Thapa M, Neopane AK, Singh UK, Aryal N, Agrawal $K$, Shrestha B. Nutritional status of children in two districts of the mountain region of Nepal. J Nepal Health Res Counc 2013;11(25):235-39.

5. Bloss E, Wainaina F, Bailey RC. Prevalence and predictors of underweight, stunting, and wasting among children aged 5 and under in Western Kenya. J Trop Pediatr 2004;50(5):260-70.

6. Goon DT, Toriola AL, Shaw BS, Amusa LO, Monyeki MA, Oluwadare A et al. Athropometrically determined nutritional status of urban primary school children in Makurdi, Nigeria. BMC Public Health 2011;11:1-8.

7. Fetuga $M B$, Ogunlesi $T A$, Adekanmbi $A F$, Alabi AD. Nutritional status of semi-urban Nigerian school children using the 2007 WHO Reference Population. West African J Med 2011;30(5):331-6

8. Rijal P, Sharma A, Shrestha S, Upadhyay S. Nutritional assessment of children at Nepal Medical College Teaching Hospital. Health Renaissance 2011; 9(3):184-8.

9. Sah N. Determinants of child malnutrition in Nepal: A case analysis from Dhanusha, central terai of Nepal. J Nepal Health Res Counc 2004;4(4):50-4.

10. Kandala NB, Madungu TP, Emina JB, Nzita KPD, Cappuccio FP. Malnutrition among children under the age of five in the Democratic Republic of Congo. BMC Public Health 2011;11:1-15.

11. Ruwali D. Nutritional status of children under five years of age and factors associated in Padampur VDC, Chitwan. Health Prospect 2011;10:14-8.

12. Sapkota VP, Gurung CK. Prevalence and predictors of underweight, stunting and wasting in under-five 
children. J Nepal Health Res Counc 2009;7(15):1206.

13. Mengistu K, Alemu K and Destaw B. Prevalence of malnutrition and associated factors among children aged 6-59 Months at Hidabu Abote District, North Shewa, Oromia Regional State. J Nutr Disorders Ther 2013 doi; http://dx.doi. org/10.4172/2161-0509.T1-001. 